\section{Racemose Hemangioma of Retina with Vein Occlusion}

Sir,

Racemose hemangioma of retina is a sporadic benign congenital phacomatoses in which simple or complex arteriovenous (AV) communications ${ }^{1}$ may occur as solitary lesion or in $30 \%{ }^{2}$ of cases as part of Wyburn Mason syndrome (WMS). WMS also termed retinoencephalofacial angiomatosis, ${ }^{1}$ is characterised by additional $\mathrm{AV}$ communications affecting ipsilateral brain, mandible, orbit, and face. Retinal racemose hemangioma $(\mathrm{RRH})$ is usually non-progressive but may occasionally be complicated by hemorrhage, leakage and vascular occlusion. ${ }^{3}$ No specific treatment has been defined except for periodic follow-ups for early detection of complications. ${ }^{2}$ Here, we document a case of RRH complicated by central retinal vein occlusion.

A 35-year married female with no known comorbids presented to us with complain of decreased vision in right eye for the last six months. It was painless and sudden in onset. It was her first consultation for this problem. No history of trauma, use of any medication, and presence of any systemic complain was elicited. Her visual acuity after correction was 1/60 OD and 6/6 OS. Near vision was $\mathrm{N}-18$ in right and $\mathrm{N}-6$ in left eye, respectively. Intraocular pressure was $14 \mathrm{mmHg}$ in both the eyes. Right relative afferent pupillary defect was present. Anterior segment examination and gonioscopy were unremarkable for both the eyes. On fundoscopy (Figure 1), right eye showed severe vascular tortuosity and engorgement along with extensive deep blot and flame shaped hemorrhages involving all quadrants of retina. Optic disc was edematous and hyperaemic. Several large calibre tortuous blood vessels extending circumferentially from disc were seen. Macular reflex was dull. A cotton wool spot was seen in inferotemporal quadrant. Left eye fundus was normal. In fundus fluorescein angiography (Figure 2), the early frames revealed masking of choroidal fluorescence corresponding to retinal hemorrhages. Later, frames showed numerous large calibre tortuous anastomosing vessels extending from disc in all directions. No leakage from these vessels and areas of capillary non-perfusion could be identified. OCT revealed macular edema with thickness of $1023 \mu \mathrm{m}$. Diagnosis of group $3 \mathrm{RRH}$ with central retinal vein occlusion was made. MRI brain was done to rule out any coexisting midbrain and mandibular AV malformation; and was found normal. Intravitreal bevacizumab injections were suggested for the treatment of central retinal vein occlusion. The patient was advised follow-up

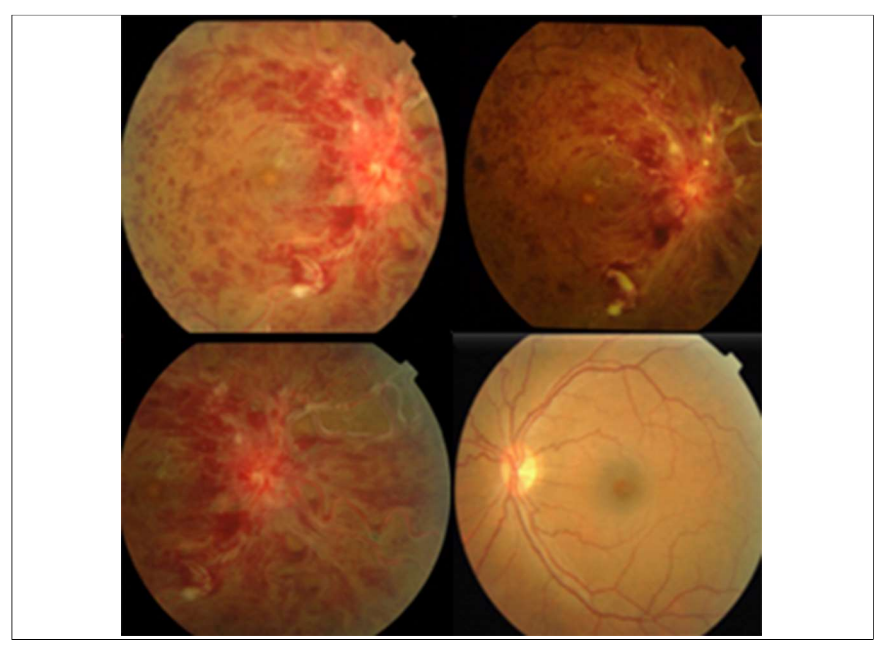

Figure 1: Fundus photographs.

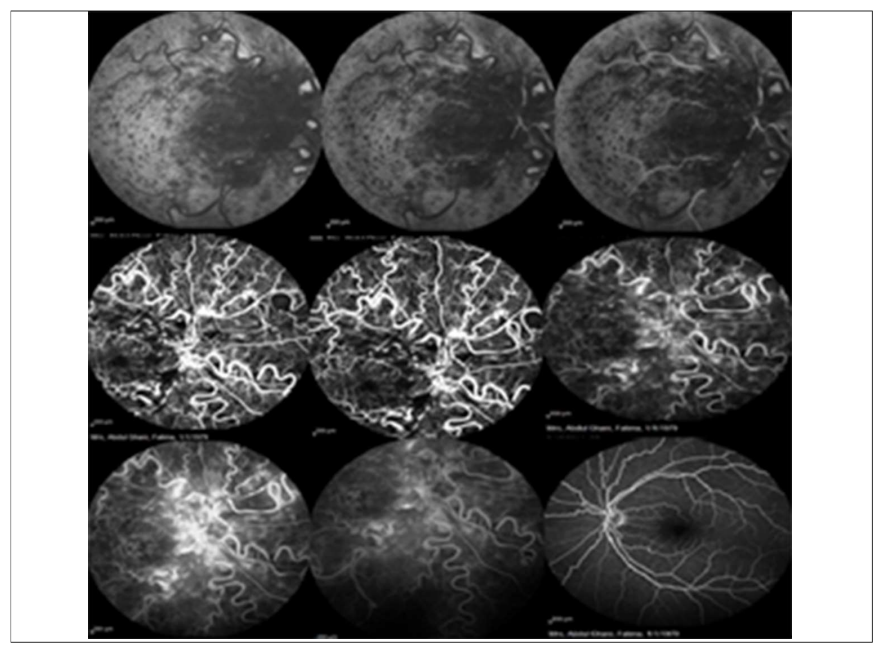

Figure 2: Fundus fluorescein angiogram.

to monitor disease progression and to keep a look out for other possible complications.

Patients with RRH maintain good vision unless complications develop. The reported complications ${ }^{3}$ include vein occlusion $(46.8 \%)$, hemorrhage $(34.38 \%)$, macular edema $(9.38 \%)$, rubeotic glaucoma $(6.25 \%)$, and retinal detachment $(3.13 \%)$. No specific treatment has been defined for $\mathrm{RRH}$, but the vision threatening complications can be managed accordingly. Options 3,4 include intravitreal anti-VEGF and steroid injections, laser therapy, vitrectomy, and glaucoma drainage device. Patients with concurrent midbrain AV malformations, 5,6 may develop stroke, cranial nerve palsies and seizures. Mandibular malformations may result in profuse bleeding during dental procedures.

It is evident from the above discussion that the management of RRH calls for frequent follow-ups for early detection and management of vision threatening 
complications. Moreover, evaluation for concurrent systemic AV malformations should always be carried out.

\section{CONFLICT OF INTEREST:}

Authors declared no conflict of interest.

\section{AUTHORS' CONTRIBUTION:}

RC: Data collection and management.

AR: Manuscript writting.

\section{REFERENCES}

1. Shields CL, Douglass A, Higgins $T$, Shields JA. Retinal hemangiomas: Understanding clinical features, imaging and therapies. Retina Today 2015.

2. Ferreira FM, Barbosa AF, Paiva MC, Loureiro AJR. Retinal racemose hemangioma: Case report. Revista Brasileira de Oftalmologia 2011; 70:303-5.

3. Qin X, Huang $C$ and Lai $K$. Retinal vein occlusion in retinal racemose hemangioma: $A$ case report and literature review of ocular complications in this rare retinal vascular disorder. BMC Ophthalmol 2014; 14:101.

4. Miguela M, Carol S, Brian M, Hakan D, Jerry S. Retinal racemose hemangioma. Retina 2005; 25:936-7.

5. Eskandri MR, Rahimi-Ardabili B, Javadzade A. Racemose hemangioma type 2: The first case report from the Middle East. Int Ophthalmol 2013; 33:95-7.

6. Bechrakis NE, Kreusel K. Retinal tumors in adults: Diagnosis and management. Expert Rev Ophthalmol 2011; 6:347-61.

Rabia Chaudhry and Areej Riaz

Department of Ophthalmology, Jinnah Postgraduate Medical Centre, Karachi, Pakistan

Correspondence to: Dr. Rabia Chaudhry, Department of Ophthalmology, Jinnah Postgraduate Medical Centre, Karachi, Pakistan

E-mail: rabiachaudhry19@gmail.com

Received: April 04, 2019; Revised: June 19, 2019; Accepted: June 21, 2019 